\title{
EAP and the Status of the ESL Professional at the University of Kansas ${ }^{10}$ Marcellino Berardo
}

This essay is inspired by Turner’s 2004 paper called “Language as Academic Purpose.” In the paper, Turner makes the point that the study and mastery of language itself is an academic pursuit. She also notes that English for Academic Purposes (EAP) is not seen on par with other disciplines in academia. I agree with Turner on both accounts and use her work to outline and comment on six different contexts in which ESL professionals, including those of us at the AEC, practice our profession. Then I offer a critical look at EAP at the Applied English Center with the intent of advancing our professional status at the University of Kansas. I conclude by stating my reasons why EAP is no different from other disciplines.

\section{EAP: An Introduction}

EAP stands for English for academic purposes. I see EAP as a broad umbrella discipline that centers on English language teaching and learning as well as the (socio-academic) linguistic investigation of all uses, meanings and forms of English in academia. This includes research into understanding how English constructs, interprets, expresses, and disseminates disciplinary knowledge. I also include under the larger umbrella of EAP, the teaching of academic English to native speakers of English who are unfamiliar with English as it is used in the university setting.

For me, EAP includes every kind of English language use at the university. Some examples are the language of (a) lectures, (b) discussion groups, (c) scientific laboratories, (d) field work, (e) art studios, (f) music practice rooms, (g) textbooks and other academic books, (h) literature and literary analysis, (i) peer-reviewed journals, (j) email, (k) faculty and student senate, (l) faculty meetings, (m) office hours, (n) conferences, (o) university administration, (p) application forms and curricula vitae, (q) writing centers, (r) technology, (s) libraries, (t) health clinics, (u) university orientations, (v) college athletics, (w) recreation centers, (x) student organizations, (y) dormitories, and (z) fraternities and sororities.

Although all English language use at the university falls within my broad characterization of EAP, we at the AEC focus mainly on teaching the scholarly use of English as a second language. ${ }^{11}$ Our instruction emphasizes the English typical of university lectures, ESL textbooks, non-ESL textbooks, and journal articles.

\section{EAP: Six Different Contexts in which We Practice Our Profession ${ }^{12}$}

Before we can examine the status of the ESL professional at the University of Kansas, we need to consider the different contexts that frame our profession because the different contexts affect the way we are perceived by the university, our colleagues in other disciplines, our students and their parents and sponsors.

\section{Context 1: The Short-cut Mentality}

English for academic purposes began because speakers of other languages were studying in English speaking countries where the medium of instruction was English. In this context, EAP was seen as a precondition for academic success. The idea behind this early view of EAP was for students to quickly learn enough English to begin "real” academic work. International students were to move through the language program as quickly as possible since English was not the reason why they came to study in English speaking countries. The more time students spent on English, the more expensive their education would be. As a result it was in the best interest of EAP students, parents, and sponsors to get the student past the language requirement as quickly as possible.

\footnotetext{
${ }^{10}$ I appreciate feedback I received on this essay from Elizabeth Gould and Chris Sundstrom. They are, however, not responsible for any mistakes or opinions expressed in this essay.

${ }^{11}$ The Graduate Writing Program works with both native speakers and non-native speakers of English.

12 These six different contexts originally come from Turner 2004. I amend and reinterpret Turner's arguments to develop them further and apply them to the AEC.
} 
This in-and-out view of English language instruction has its merits but also lends itself to a "short-cut" mentality, which underestimates what it really takes to learn a language for academic purposes. Simply put, there is no short-cut to acquiring English for the purposes of reading, writing, and talking about intellectually challenging concepts and theories in any discipline. To achieve that level of language proficiency it takes a lot. It takes (1) much exposure, (2) interaction, (3) practice, (4) experience, (5) feedback, (6) a heightened awareness of language form and use, and (7) many opportunities for meaningful use of the language in various academic contexts. Also necessary are many social, academic, and linguistic mistakes and the personal and academic growth that arises out of making mistakes in a different culture. All this takes time. It takes much effort, too. We do disservice to our profession and we mislead our students, their parents and sponsors, and our colleagues in other disciplines if we do not discount the short-cut mentality that still exists today.

\section{Context 2: Standardized Tests}

Standardized tests such as the TOEFL and IELTS also affect the way our profession is perceived. (At the AEC, the proficiency test is the relevant standardized test.) High enough scores from the TOEFL or IELTS commonly serve as a ticket to begin "university study". With the right score, the student is considered to be proficient enough in the language to fulfill the university's English requirement for international students. If the student does not score high enough, there is an industry of classes, books, and videos that can prepare the student for the test.

Standardized tests and the industry built around them promote the idea that EAP can be separated from academia. In this context, standardized tests fail to get across the basic idea that language and disciplinary content are inseparable. Each discipline has a specific way to structure knowledge through language (Martin, 2007). Moreover, academic content is constructed from and exists as (1) general academic vocabulary (Coxhead, 2000; Hyland \& Tse, 2007), (2) specialized language or jargon (Woodward-Kron, 2008), (3) academic collocations (Durrant, 2009), (4) grammatical metaphor (Halliday \& Martin, 1993; Ryshina-Pankova, 2010), (5) other metaphors (Lakoff \& Nuñez, 2000), (6) analogies and similes, (7) hierarchical organization patterns, (8) rhetorical styles and (9) academic genres (Swales, 1990, 2004; Hyland \& Sancho Guinda 2012). This point gets obscured by standardized tests.

Unfortunately, standardized tests also have the effect of reducing EAP to a test score or another hoop to jump through to get admitted to the university. In this context, proficiency in EAP becomes just another item on the student's checklist of requirements for university admission. It is, of course, necessary to have a high level of proficiency in English to be academically successful. It is, however, misleading for the student to think that there is little more to academic English than a test score.

Standardized tests also send the message that there is finality to learning a language. The idea here is that once the student gets a 23 on the Internet-based TOEFL, for example, s/he is done. The student has finished learning English and is ready to go off and major in a discipline. Language skills, however, only increase with knowledge and experience. Writing, for example, continues to get better the more one writes, reads, discusses, and gets critiqued. Ability to use the language to make more interesting contributions in any discipline grows as knowledge of the field deepens. There is no finality to learning language and to using it in academia because content and its linguistic expression never stop developing.

\section{Context 3: Part-time Teachers}

EAP as a discipline continues to develop. In order for it to keep pace with other disciplines, it needs more full-time practitioners. Unfortunately, there has been a decades-long trend for more part-time instructors at universities and community colleges. EAP as a discipline has entered academia during this time. This explains, in part, why there are so many part-time positions at universities for EAP practitioners. Any rationale for part-time EAP professionals, however, remains confusing since there is significant demand for academic English. Part-time teachers, perhaps especially in the face of high demand for their expertise, further contribute to the 'lower status' perception of EAP as a profession. Important here is that part-time work does not offer practitioners the time or financial security to develop the discipline even more fully. The profession simply needs more full-time practitioners. 


\section{Context 4: The Deficit Perspective}

EAP students can be seen as having a linguistic deficit. Under this view, our students' lack of proficiency in English is considered a deficit that needs to be addressed. Language teaching is reduced to helping students narrow or erase the deficit they arrive with. To address this deficit, students and instructors engage in a kind of pre-academic endeavor that helps students 'get up to speed.'

When we take a 'deficit' perspective on EAP, the profession is relegated to what Swales (1990) calls the "ivory ghetto of remediation," (p. 6) playing off the metaphor of the ivory tower. ${ }^{13}$ Categorizing the profession as pre-academic or remedial learning needed only to address a deficit does not recognize the knowledge and experience international students and scholars bring with them. At the AEC, we have Fulbright scholars, other accomplished professionals, and graduate students specializing in a range of disciplines. Many of our undergraduate students come to us with a strong background in mathematics and the sciences as well as a range of other subjects from rigorous high school programs and private classes designed to prepare them for notorious college entrance exams such as the Chinese Gaokao.

These students and scholars do not need remedial learning. They need to take on the significant task of mastering highly specific ways academic English realizes critical thinking and creates and represents ever changing disciplinary knowledge. At the same time they take on this significant task, our students also need to develop the language skills relevant to discussing and writing insightfully about complex and abstract ideas from the sciences, social sciences, humanities, and professional schools. While working on how English manifests itself in critical thinking, knowledge creation, and language skills, EAP students and scholars also need to learn and apply the invisible and subtle rules of academic culture that underlie the use of English in various settings at the university. (For examples of university settings see (a)-(z) in the Introduction.) The 'deficit' perspective simply fails to recognize what it means to acquire and use academic English. More on this point is given in the next section.

\section{Context 5: Language Work is Underestimated}

Language goes unnoticed until we hear a different accent, see a grammar mistake, or have difficulty understanding a word or phrase. The automatic or subconscious nature of much of language use can mislead students, parents, sponsors, university administrators and others into underestimating what it really takes to learn a language for academic purposes. ${ }^{14}$ It can appear that language, even academic language, is easy enough to "pick up” or "brush up on.” The international student just needs to refer enough times to a good grammar book and s/he will get the hang of it. ${ }^{15}$

The problem here, of course, is that many word choice and grammar mistakes have no simple solution. For example, there exists no list of rules to ensure selection of the appropriate word, collocation, and grammatical construction for each intended thought in each written and spoken context. To illustrate some of the complexity of language, Turner (2004) gives a brief excerpt from a doctoral student's dissertation. Turner notes that the student has no problem with understanding the theoretical issues of her dissertation. The student is a good critical thinker. The student also has no problem communicating verbally. The problem is with written English.

The excerpt is one sentence long:

"The repressed and victimised 'others' in Asian formation of modernity has been totally abandoned from social consciousness for long whose life has been disregarded in the hypocritic concept of the 'humanities' conflicted with the designated sense of 'progress' through the march of economic development in the modern era." (p. 100)

\footnotetext{
${ }^{13}$ As cited in Turner (2004).

${ }^{14}$ Our monolingual colleagues can be misled to underestimate what it takes to learn a language for academic purposes if they did not go through the process.

${ }^{15}$ This superficial view of language learning, among other things, does not take into account the fact that language and culture are fused. The linguistic expression of cultural rules is immensely complex but necessary to the task of learning a language for academic purposes. I am not aware of a "good grammar" of the language and culture of academic disciplines. Even if one exists and is consulted, it is unlikely that the task of acquiring EAP would be significantly affected. See contexts 1, 2, and 5 for more.
} 
Turner (2004) takes two pages to explain the language of this sentence and the difficulty with understanding it. She attributes difficulties to "word choice...concept[s] obscured by overwrought wording and referencing all running together in three consecutive adverbial phrases...stylistic awkwardness...foregrounding ... modifying... [and] clause structures rather than adverbial phrases" (pp.100-102). These kinds of issues, particularly when fused together in one sentence, go beyond simple 'surface grammar clean-up.'

The point here is that academic discourse requires sophisticated argumentation, which in turn requires sophisticated selection and arrangement of specialized vocabulary, collocations, and grammar. There is nothing remedial about it. Moreover, these issues only lead to frustration if a short-cut mentality exists. Standardized tests such as the TOEFL or IELTS and commercial test prep classes also do not help because these language issues manifest themselves particularly when original, critical thought gets converted to words, collocations, grammar, specific examples, organization, etc. The deficit perspective is also not helpful. The doctoral student does not need pre-academic work to fill a gap in her knowledge of English. What is needed is a deeper appreciation of the role language plays in thinking critically, making new knowledge and representing existing knowledge.

\section{Context 6: Content over Language}

Universities seem to separate content from language and value content over language. In this view, EAP is seen as separate from and a prerequisite to 'real' academic work. Isolated from real meaning and taught as a decontextualized skill, language proficiency appears "intellectually empty.” Once a certain level of proficiency is achieved, the task has been completed. Content, on the other hand, only continues to deepen. The student or scholar is never done investigating, discovering, or creating content.

Contributing to the perception of EAP as intellectually less significant than "content disciplines" are the materials used in EAP classes. Turner (2004) reviews a study that found that students perceived the writing in EAP classes to be less of an "intellectual challenge" than the writing in other disciplines. In response, Turner wants EAP practitioners to be familiar with content from another discipline because it is easier for students to focus on language when the content is intellectually stimulating. Our goal, then, is to teach "the language of intellectually challenging content” (p.105).

We can now ask, how familiar should we become with “intellectually challenging content”? In a university setting, a graduate degree in a particular discipline is more likely to be acknowledged. However, EAP practitioners do not typically have graduate degrees in a discipline other than their own (e.g., education or applied linguistics) ${ }^{16}$ Even if EAP professionals went out to get graduate degrees in other disciplines, what disciplines should we choose? Furthermore, should we stop at a master's degree? Without a Ph.D. in another discipline we can easily be seen as "stepping on the toes" of our colleagues. At worst, we can be seen as "hacks" trying to teach content we have little expertise in. Not wanting to tread on academic territory of our colleagues and not wanting to appear as "hacks", we retreat back to the familiar ground of “content-based” pedagogy lacking in real "intellectually challenging content.”

I interpret "intellectually challenging content" to be the same kind of content taught in General Education courses such as those in the College of Liberal Arts and Sciences. In a typical chemistry or psychology textbook, the fundamental principles of the discipline are defined, explained, and illustrated. I see no big reason why EAP should veer away from using fundamental principles of disciplines in our content-based AEC classes, especially for advanced EAP courses. Many of our advanced students in levels 4 and 5 are already exposed to fundamental principles of different disciplines because they are taking General Education courses. I would argue that we should use this content because it is not only more intellectually stimulating but also more relevant to the students’ present or future educational experience.

We can address the issues of 'stepping on the toes of our colleagues' and 'language proficiency as "intellectually empty”' by making explicit (1) our purpose for using content from other disciplines and (2) the kinds of questions we ask about the

\footnotetext{
${ }^{16}$ And why should they? Sociologists, economists, professors of Spanish, etc. are not required to get graduate degrees in disciplines other than their own, so why should this be an issue for the EAP professional, especially if we do not accept the 'content over language' bias?
} 
content. First, we use content from college courses because our students are college students. We differ from our colleagues in economics, for example, in that we are less interested in what a specific economic concept, theory, fact, or opinion is. Instead, we are more interested in how that concept, theory, fact, or opinion gets linguistically interpreted. This means we need to identify the content (concepts, theories, facts, opinions etc.) and examine how that content is realized in (a) words and jargon, (b) academic collocations, (c) grammar, (d) metaphors, (e) examples, (f) organization, (g) argumentation, etc. We are not treading on our colleagues' territory because we are the experts in teaching words, collocations, grammar, and metaphors to speakers of languages other than English. We are also the experts in teaching international students how to develop and organize examples in an English way. An emphasis on the use of language for paragraph development, organization, and styles of argumentation also fit naturally in a language class as opposed to a non-language class.

This kind of attention to linguistic expression is a response to what I call the 'how' question in EAP. The 'how' question asks 'how does language construct and disseminate content?' and 'how does the language reveal the way the content is perceived?' In contrast to the 'how' question is the 'what' question, which is basic to other disciplines. The 'what' question asks, 'what is the basic content of the discipline?' At issue here is the idea that the 'how' and 'what' questions are dependent on the same content. There can be an emphasis on one or the other; but, in fact, the two questions are fused to the same content. They provide two lines of inquiry into the same content and two ways to teach the same content.

\section{EAP: A Critical Look at Our Profession at the University of Kansas}

EAP professionals at the University of Kansas work within the different contexts described in (1)-(6) above. Because our profession is framed by these different contexts, we are implicitly perceived to be different from disciplines that are not framed by (1)-(6) above. For example, specific to Context 2: Standardized Tests, we exist as part of a university English language requirement relevant only to a small but important part of the student body, international students. If international students do not have a 23 or higher on all parts of the Internet-based TOEFL or part scores of 6.0 or higher with a total score of 6.5 on the IELTS before coming to KU, then they need to fulfill their English language requirement by attending our classes and passing our proficiency test. This positions us as a pre-academic unit. A student only needs a score of 160 on our standardized test (proficiency test) to be ready for "real” academics. Institutionally, this sends the message that English for academic purposes is not on par with other disciplines.

Also sending the message that EAP is different from other disciplines at the university is the fact that our students cannot major or minor in applied English at the AEC. In fact, we do not offer a major or minor even though we are accredited by the Commission on English Language Program Accreditation (CEA), staffed by faculty holding Ph.D.'s and MA's, and recognized as EFL teacher trainers by the US State Department and other institutions that offer grant monies.

To be fair, our position at the university is more complex than this. Institutionally we also appear to send the message that EAP is equivalent to other disciplines. Students who receive passing grades (A, B, or C) in ESLP courses can earn up to 10 general credits toward graduation. Although the 10 credits do not count specifically toward the university's foreign language requirement, our students do fulfill the foreign language requirement by passing out of all three AEC classes (Speaking/Listening, Reading/Writing, and Grammar for Communication.) Students who pass out of at least one AEC class can also enroll in General Education (or other) courses in the same semester they are taking other required ESL classes. By earning credits toward graduation, fulfilling the university's foreign language requirement, and simultaneously taking General Education and ESL courses, the university sends the message that the AEC is more than a pre-academic unit.

Although our position at the university is complex, there is an advantage to the prerequisite aspect of our work here. The advantage is that our contribution is required as long as the university accepts international students with Internet-based TOEFL scores under 23 and IELTS scores under 6.0-6.5. The university’s English language requirement for international students gives us the opportunity to practice, interpret, and develop our profession. This opportunity provides us with a 
chance to advance the profession and to integrate deeper into the university. The question now is, 'how do we take this opportunity and develop our profession?’

There are more reasons why EAP professionals are not seen on par with professionals of other disciplines. Perhaps the most important is that our terminal degree is a master's degree. This puts us at a disadvantage in a university setting where most of our colleagues have doctoral degrees. A graduate degree, however, is different from the pursuit of intellectually interesting questions. Our profession is positioned to investigate and teach what could be one of the most important questions of the current knowledge-based era: 'what is the relationship between language and disciplinary knowledge?' As a discipline, EAP is positioned to investigate and teach how English constructs disciplinary knowledge with the intent of bettering the human condition through science, medicine, journalism, engineering, technology, economics, the humanities, etc. The more we understand the language-knowledge relationship, the more effective teachers of current and future international students and scholars we become.

In EAP the language-knowledge relationship is particularly interesting because English is the single most important language in world scholarship. Cutting edge ideas are created, developed, and disseminated in English. EAP professionals are at the intersection of the advancement of world knowledge, English language, and the careers of individual students and scholars.

EAP practitioners should keep in mind that we marginalize ourselves when we talk about EAP only in terms of skills or a certain proficiency level or in relation to a standardized test. We also marginalize ourselves when we talk about our practice only in terms of pre-academic work or in opposition to university courses (e.g., KU classes vs. AEC classes). We also limit ourselves if we only talk about helping students "clean-up” their English without acknowledging the intricate and complex role of English in academia and in the advancement of world knowledge, along with all its consequences. Academic English is affecting the world. It affects what we learn and know, how we learn and know, and how we interact. We need to take into account the role of English in world academia and what it means to investigate and teach it in order to more fully articulate what it means to be an EAP professional.

\section{EAP: Why We Should Have Equal Status}

EAP should have the same status as other disciplines at the university. Academic disciplines are organized, knowledge generating organisms. EAP is no different. EAP explains how we know and represent fields such as economics, biology, and chemical engineering. Specifically, EAP is the discipline that explains and teaches the role language plays in the creation, interpretation, and dissemination of disciplinary knowledge. Our data set consists of the sum of academic language produced by our colleagues in all disciplines. We look at how English is used and how it gets meaning from the academic context. All corners of academia are relevant.

We develop theories to explain the relationship among language, pedagogy, and knowledge (for an excellent example see Christie and Martin, 2007). We publish in academic journals such as the Journal of English for Academic Purposes and TESOL Quarterly. We apply our theories (and professional experience) to develop curricula and materials to teach students how to use English for their academic purposes. We also teach and train EFL instructors and professionals in other fields who want to teach in English and/or want to access and publish in English language journals and other media. We adjust our practice as we learn more about how English is used for academic purposes and how best to teach our students and train other teachers and professionals to use academic English. In these ways, EAP is no different from other disciplines at the university.

Of course not every lecturer, language specialist, and administrator at the AEC is involved in all aspects of the discipline. Most of us specialize in teaching language skills, content, grammar, and vocabulary. Some of us are interested in theory and others in the application of theory to the classroom. Some straddle theory and application to develop curricula and write materials. Some focus on assessment while others on socio-political and ethical concerns. Others emphasize crosscultural communication, cultural adjustment issues, or other aspects of international education. Others are active in IEP administration and grant writing. We also have specialists in CALL, second language acquisition, and linguistics. Too few 
of us are non-native speakers of English ${ }^{17}$ but most of us know another language and/or have lived abroad. Whatever our specialty and background, we are all united by (1) the data set (academic English), (2) our interest in language, pedagogy, and knowledge, and (3) the mission to teach students and train non-native English speaking colleagues to use English for academic purposes.

As EAP professionals we are part of international education at KU. We team up with our students and our international and domestic colleagues in other disciplines to produce the next generation of world professionals. Some of those professionals will work on cures for cancer and other diseases. Some will develop better economic theories and practices and find solutions to problems of food and energy production and distribution. A very select few will even become president of their countries. (President Juan Manuel Santos of Colombia studied at KU.) As we continue to interpret, practice, and develop our profession, I suggest that we promote the central importance of English in knowledge creation and world academia.

\section{References}

Christie, F. \& Martin J. R. (Eds). (2007). Language, knowledge, and pedagogy: Functional linguistic and sociological perspectives. New York: Continuum.

Coxhead, A. (2000). A new academic word list. TESOL Quarterly, 34(2), 213-238.

Durrant, P. (2009). Investigating the viability of a collocation list for students of English for academic purposes. Journal of English for Academic Purposes, 28, 157-169.

Halliday, M. A. K., \& Martin, J. R. (1993). Writing science: Literacy and discursive power. London: The Falmer Press.

Hyland, K. \& Guinda, C. S. (2012). Stance and voice in written academic genres. New York: Palgrave Macmillan.

Hyland, K. \& Tse, P. (2007). Is there an “academic vocabulary?” TESOL Quarterly, 41(2), 235-253.

Lakoff, G. \& Nuñez, R. E. (2000). Where mathematics comes from: How the embodied mind brings mathematics into being. New York: Basic Books.

Martin, J.R. (2007). Construing knowledge: a functional linguistic perspective, in Christie, F., Martin. J. R. (Eds.), Language, knowledge, and pedagogy: Functional linguistic and sociological Perspectives (pp.34-64). New York: Continuum.

Ryshina-Pankova, M. (2010). Toward mastering the discourses of reasoning: Use of grammatical metaphor at advanced levels of foreign language acquisition. Modern Language Journal, 94(2), 181-197.

Swales, J. (1990). Genre analysis: English in academic and research settings. Cambridge: Cambridge University.

Swales J. (2004). Research genres: explorations and applications. Cambridge: Cambridge University.

Turner, J. (2004). Language as academic purpose. Journal of English for Academic Purposes, 3, 95-109.

Woodward-Kron, R. (2008). More than just jargon - the nature and role of specialist language in learning disciplinary knowledge. Journal of English for Academic Purposes, 7, 234-249.

\footnotetext{
${ }^{17}$ This is unfortunate because most of our profession consists of teachers who are non-native speakers of English.
} 